\title{
An Indoor Navigation Support for the Student Halls of Residence using Augmented Reality: A Design Perspective
}

\author{
Dinna Nina Mohd Nizam ${ }^{1 *}$, Lim Wei Shin ${ }^{1}$, Zaidatol Haslinda Abdullah Sani', \\ Pornpon Thamrongrat ${ }^{2}$ and Nooralisa Mohd Tuah ${ }^{1}$ \\ ${ }^{1}$ Faculty of Computing and Informatics, Universiti Malaysia Sabah, 87000 W.P.Labuan, Malaysia \\ ${ }^{2}$ School of Informatics, Walailak University, Nakhon Si Thammarat, 80161 Thailand
}

\begin{abstract}
Augmented Reality (AR) technology has become increasingly popular due to its potential use in an indoor environment. AR technology enables virtual information, such as navigation instructions, to be merged into the actual environment via a mobile screen. Using an AR-based Indoor Navigation speeds uptime while also being interactive in searching for a particular building location. Every year when new semester students enrol in the university, some students will have difficulty finding a particular location on the campus. The most searched for building upon arrival at the university is the student halls of residence. While searching for it, students waste time asking others for information or looking for a nearby campus map. Therefore, this project investigates the requirements needed for an AR-based indoor navigation application to be applied within the student halls of residence and identifies technical issues through a small-scale prototype development within a small navigational area. Seventy-one students participated in the feasibility study by responding to a set of questionnaires related to the Student Residence AR indoor navigation application. At the same time, four users with and without previous experience with AR applications evaluated

ARTICLE INFO

Article history:

Received: 13 April 2021

Accepted: 30 July 2021

Published: 08 October 2021

DOI: https://doi.org/10.47836/pjst.29.4.23

E-mail addresses:

dinna@ums.edu.my (Dinna Nina Mohd Nizam)

bwhiteshin1997@gmail.com (Lim Wei Shin)

linda.sani@ums.edu.my (Zaidatol Haslinda Abdullah Sani)

pornpon.th@wu.ac.th (Pornpon Thamrongrat)

alisa.tuah@ums.edu.my (Nooralisa Mohd Tuah)

* Corresponding author the prototype application. The results identified that the more the students have difficulty searching, the more they require additional time to reach their destination and seek help from others, an excellent reason to implement the Student Residence AR indoor navigation. In addition, the prototype evaluation results discussed issues related to arrow path confusion, distance accuracy,
\end{abstract}


assistive guideline, and software development challenges in AR development that could be beneficial to future developers and researchers.

Keywords: AR indoor navigation, AR prototype development, augmented reality, design perspective, student halls of residence

\section{INTRODUCTION}

Augmented Reality (AR) navigation technology has allowed indoor navigation in buildings for various users and environments. AR indoor navigation has guided users to navigate easily within complex buildings (Gerstweiler, 2018). Verma et al. (2020) carried out an AR indoor navigation application within a hospital and reported that the application provided a better user experience to the users rather than 2D Maps. Meanwhile, Yoon et al. (2019) reported that implementing an AR indoor application through a smartphone for visually impaired people was significant, and they presented a guideline for future studies. The latter motivates our study to apply an AR indoor navigation application in student residence halls in a branch campus.

Every year when new students enrol into the university, there will be those who will have some difficulty searching for a specific location on the campus. The most searched for building upon arriving on campus is the student halls of residence. Upon arrival and registration, a student begins to search for their accommodation to keep their bulky belongings. Roaming around in search of a building with their belongings in hand would not be a pleasant first-day experience at the campus for them. Furthermore, the environment layout of campus as compared to hospital wards and hotel rooms are quite different. Hospitals prioritise the safety of their patients; hence rooms are designed differently. Some have single rooms, double rooms, and a whole ward layout, while hotels have different room layouts. In this study, every room in the student halls of residence has the same layout. Therefore, this study aims to comprehend the requirements for university students implementing a Student Residence AR indoor navigation application. The contribution of this study is threefold; first, analyse the possibility of implementing the Student Residence AR indoor navigation application among the students. Second, to identify the user requirements needed for the Student Residence AR indoor navigation application among the students. Third, to identify technical requirements for developing a Student Residence AR indoor navigation application through a pilot study before implementing it on a bigger scale.

AR is the technology that blends the real-world environment with the virtual world via digital objects (Siltanen, 2012). It is a technology platform that integrates digital visual content into the real-world environment of the user. AR has brought significant advancement in several application areas such as education (Sani et al., 2020; Cai et al., 2019; Vargas et 
al., 2020), health care (Bui et al., 2021; Gerup et al., 2020), tourism (Williams et al., 2020; Yung \& Khoo-Lattimore, 2019), and also in navigation support (Satriadi et al., 2019). In addition, AR technology can be used for both indoor and outdoor activities (Arantes \& Lamounier Jr, 2018).

AR in navigation has helped people by giving them a reference or direction in wayfinding, which has changed how people explore a new place. Currently, AR navigation applications are widely performed outdoors, such as for test car navigations (Uchida et al., 2017), pedestrian wayfinding (Dong et al., 2021; Tran \& Parker, 2020), and sightseeing navigations (Kato \& Yamamoto, 2020; Sasaki \& Yamamoto, 2021). Nevertheless, indoor navigation has also gained plausible attention in research as well as in technology adoption. For example, Codina et al. (2019) investigated AR navigation in buildings for emergencies or low visibility conditions and reported that AR navigation was significantly beneficial for the staff in finding their ways in that state of urgency or particular events. Furthermore, de Oliveira et al. (2017) added the usefulness of indoor AR navigation for users with limited mobility, such as wheelchair users sustained safe navigation.

Additionally, this paper surveyed a number of AR navigation articles in the literature to comprehend the AR application in the field. Table 1 summarises the surveyed articles and their study objectives and outcome or results obtained from the study. Findings show that indoor navigation can be used widely, whether it is for any navigation purposes or direction precision and effectiveness. Therefore, this study has strong support in implementing a Student Residence AR indoor navigation application, particularly for students entering the student halls of residence for the first time.

There are six types of AR technology, and they are classified into two categories (Figure 1); triggered-based and view-based augmentation (Edwards-Stewart et al., 2016). The widely known triggered-based augmentations are the marker-based AR and location-based AR, while the general view-based augmentation is the markerless AR. The marker-based AR approach uses a marker presented in a paper-based or physical object to trigger the augmentation (Siltanen, 2012). In comparison, the location-based AR is activated by the Global Positioning System (GPS) location and pairs the desired destination (Chanphearith $\&$ Santoso, 2016). Thus, the combination of GPS, compass sensors, trackers, and computer displays determines the location-based AR implementation (Billinghurst et al., 2014).

Conversely, the markerless AR method uses a real-world static view or real-life object as a marker. Thus, the tracking method combines the natural features of a particular real-life object by detecting the targeted object's edges, corners, and texture (Jumarlis \& Mirfan, 2018). In addition, markerless AR also uses GPS and compass to provide data based on the user's location. This data then determines what AR contents the user receives in a particular area, producing maps and directions at the end. 
Table 1

Summary of several indoor augmented reality navigation studies

\begin{tabular}{|c|c|c|}
\hline Articles & Study Objective & Outcome/ Result \\
\hline D. Khan et al. (2019) & $\begin{array}{l}\text { Time efficiency/ } \\
\text { Distance accuracy }\end{array}$ & AR navigation is efficient, accurate, and user friendly. \\
\hline Codina et al. (2019) & Distance accuracy & $\begin{array}{l}\text { AR system is useful in low visibility situations and } \\
\text { proved to be helpful. }\end{array}$ \\
\hline Vidhyavani et al. (2019) & $\begin{array}{l}\text { Object recognition } \\
\text { accuracy }\end{array}$ & $\begin{array}{l}\text { The mobile camera allows various objects to be } \\
\text { supplied into the AR application. }\end{array}$ \\
\hline R. U. Khan et al. (2019) & $\begin{array}{l}\text { Human cognitive } \\
\text { workload/ Time } \\
\text { efficiency }\end{array}$ & $\begin{array}{l}\text { Indoor AR system provides useful information without } \\
\text { having any physical equipment or connection. }\end{array}$ \\
\hline Ghantous et al. (2018) & Distance accuracy & AR navigation results are positive and satisfying. \\
\hline Gerstweiler (2018) & Distance accuracy & $\begin{array}{l}\text { Good performance was reported in guiding users with } \\
\text { AR. }\end{array}$ \\
\hline De Oliveira et al. (2016) & Optimal routes & $\begin{array}{l}\text { AR has the ability to identify the best routes and } \\
\text { reduce potential hazards for wheelchair users. }\end{array}$ \\
\hline Yang \& Saniie (2017) & $\begin{array}{l}\text { Distance accuracy/ } \\
\text { Position estimation }\end{array}$ & $\begin{array}{l}\text { The position estimation error is reduced by a larger } \\
\text { AR marker or by using higher resolution images. }\end{array}$ \\
\hline
\end{tabular}

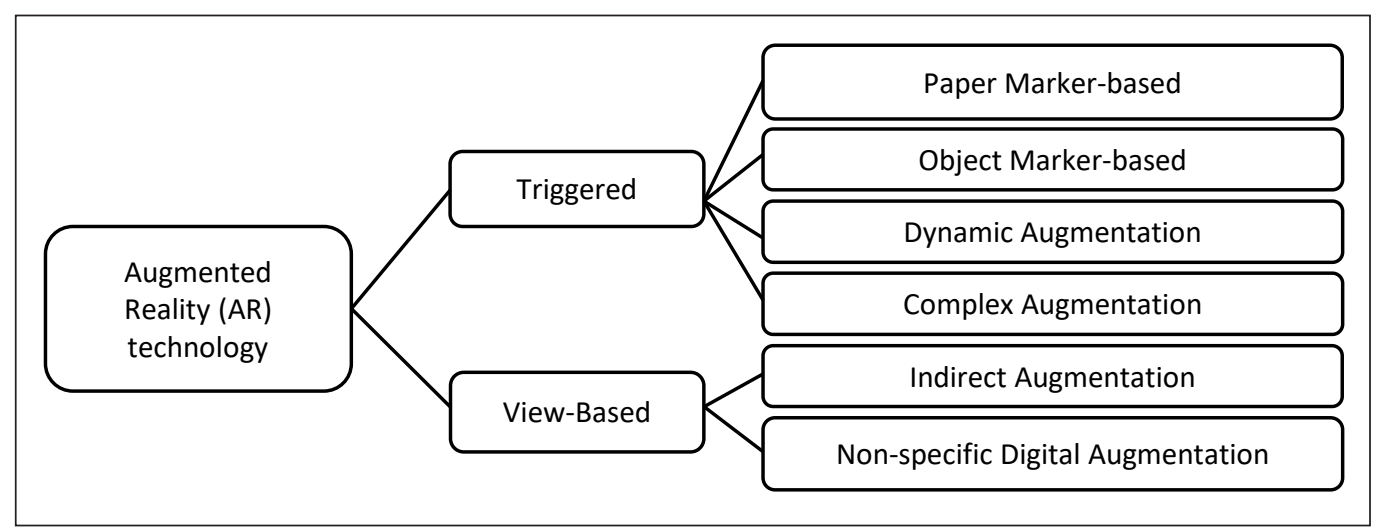

Figure 1. Augmented reality technologies classified by Edwards-Stewart et al. (2016)

The Student Residence AR indoor navigation application will adapt the markerbased AR technology to trigger augmentation for this current study. A marker-based AR technology is more relevant for a dedicated indoor navigation system that does not demand extensive installation or strong wireless connections.

\section{MATERIALS AND METHODS}

Figure 2 illustrates the study as a whole, consisting of four phases: Initial phase, Design phase, Implementation phase, and Evaluation phase. However, this paper only reports the first two phases; the initial phase and the design phase. The initial phase includes reviewing 
the literature, reviewing previous AR navigation studies, and conducting a preliminary investigation to identify user requirements reported in the results and discussion section. In the design phase, a small scale prototype pilot was built and implemented to identify technical requirements before building the larger scale prototype for the student halls of residence. As continuous work from this study, the following articles will report the other two phases; implementation and evaluation.

In the initial phase, using a simple random sampling approach, seventy-one students participated in the preliminary feasibility study conducted among 1,900 university students living in the student halls of residence of the branch campus. Online questionnaires were distributed across Year 1 to Year 4 students via google forms. Unfortunately, only a few students completed the questionnaires due to the Covid-19 Pandemic, which forced most students to return home. Approximately 36 male and 35 female students answered the survey question. The questions were divided into three sections: (1) Demographic profile, (2) User experience on current halls of residence system, and (3) User opinion on a Student Residence AR indoor navigation application. The outcomes of this feasibility study are discussed in the results and discussion section.

In the design phase, the Student Residence AR indoor navigation application utilises marker-based technology. Software such as Unity 3D and Visual Studio is used in the development of the application. Vuforia SDK package is added to the Unity 3D application to enable augmented reality functions. C\# Programming Language is also used to write

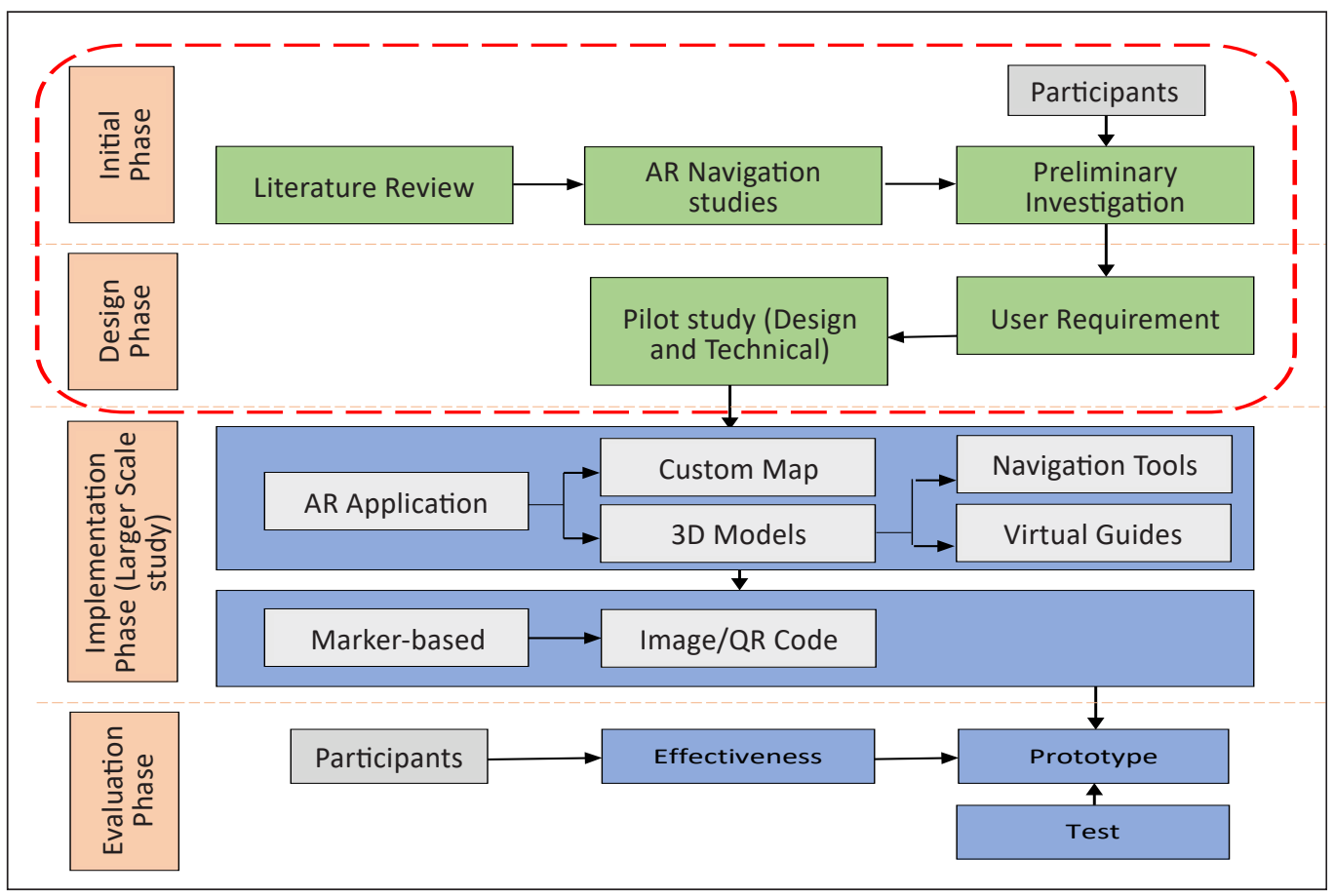

Figure 2. Conceptual Design of the entire work and focus of this paper is indicated in the red dashed line area 


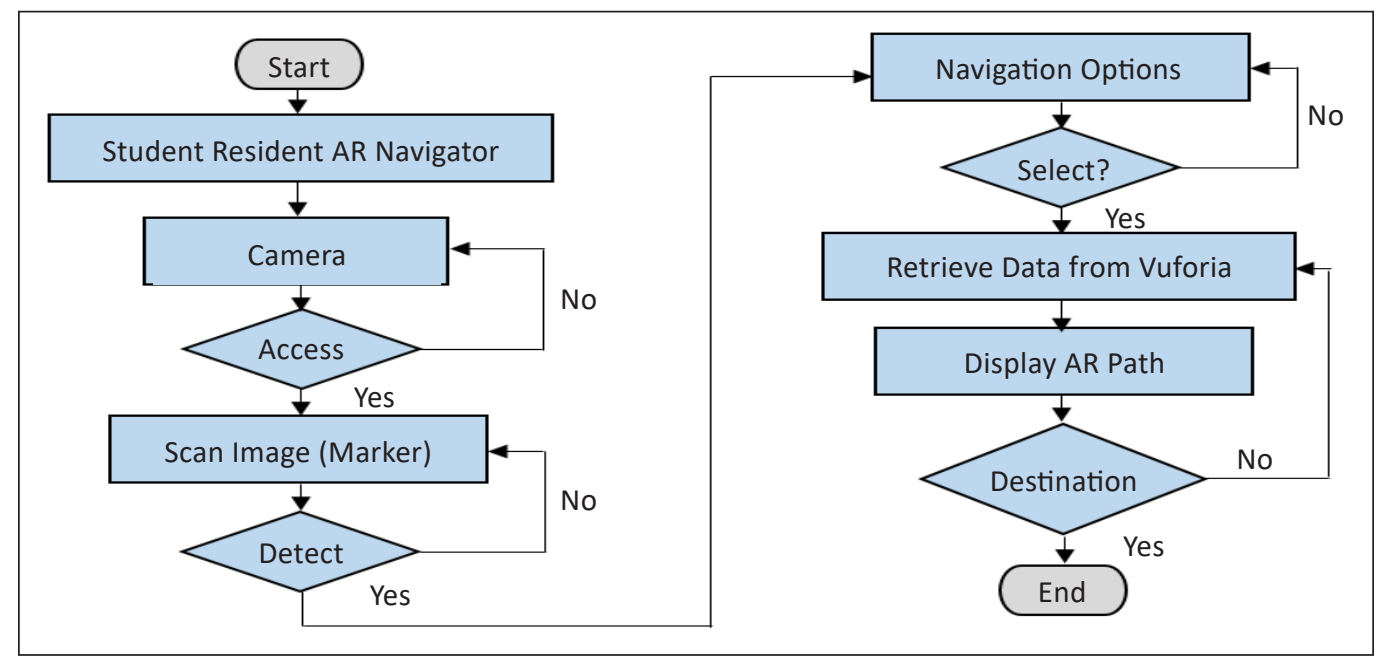

Figure 3. The application algorithm flow for both the small-scale and large-scale prototype

scripts that allow certain functions to be called on the application's component (object). Before a large-scale application is developed in the implementation phase, a small-scale prototype was developed and reported in this paper. This small-scale prototype was done to identify technical issues and to optimise resources.

Figure 3 presents the algorithm flow for both the small-scale prototype and the largescale Student Residence AR indoor navigation application. This application uses the ARcodes as markers because they are much easier to be recognised by the camera and user. The AR code, known as the Augmented Reality Code, is a 2D barcode in the form of pixel squares in a box and redirects the user to an AR website or mobile application. Once the Student Residence AR indoor navigation application recognises the marker (scans image) and identifies the user location at this point, the application displays the navigation options (e.g., Living Room, Store, Kitchen, Room, Room 2). After a selection has been made, the application calculates both the marker's position and destination. The position of the computer-generated content can be affected by any change in the position of the real-world object. Therefore, the more refined the application can identify a particular physical object, the more accurate the digital data layout will be. These calculations and measurements are conducted through the Vuforia Engine Platform. Whenever a user changes routes by accident, the Vuforia Engine Platform recalculates the destination and displays the user's corrected path.

\section{RESULTS AND DISCUSSION}

A preliminary study was conducted to assess the feasibility of implementing a Student Residence AR indoor navigation application for students in the student halls of residence. Table 2 demonstrated that students had difficulty finding their particular room when they 
first arrived at the university's halls of residence. In addition, there was a significant relationship between Searching Difficulty and both Genders $\left(\mathrm{x}^{2}(1)=5.04 ; p<.05\right)$, with female students struggling more than male students.

Table 3 reports Searching Difficulty and the practice student applied when searching a particular room in the residence halls. The relation between Searching Difficulty and Searching Support practice was significant, $\mathrm{x}^{2}(4)=24.26 ; \mathrm{p}<.01$. From the data, Table 2 the majority of students struggled with searching and sought assistance from others. There were only a few students who had no problems.

Searching difficulty of both genders

\begin{tabular}{lccc}
\hline Genders & Yes & No & Chi - Square \\
\hline Male $(\mathrm{n}=36)$ & 27 & 9 & $\mathrm{df}=1$ \\
Female $(\mathrm{n}=35)$ & 33 & 2 & $\mathrm{x}^{2}=5.04$, \\
Total & 60 & 11 & $\mathrm{p}=.02$ \\
\hline
\end{tabular}

Table 3

Searching difficulty on searching support

\begin{tabular}{lccccc}
\hline & No. & Had Difficulty & No Difficulty & \% & Chi-Square \\
\hline By Floor Map & 26 & 23 & 3 & 23.9 & df $=4$ \\
Ask Help From Others & 39 & 39 & 0 & 35.8 & $\mathrm{x}^{2}=24.26$, \\
Own Explore & 38 & 30 & 8 & 34.9 & $p=.00$ \\
No Need Assistance & 6 & 3 & 3 & 5.5 & \\
Total & 109 & & & 100 & \\
\hline
\end{tabular}

Table 4

Searching difficulty on time spent and AR awareness

\begin{tabular}{lllll}
\hline & Searching Difficulty & Yes & No & Chi - Square \\
\hline Need (Spends) More & Had Difficulty & 44 & 16 & $\mathrm{df}=1$ \\
Time & No Difficulty & 4 & 7 & $\mathrm{x}^{2}=5.80$, \\
& Total & 48 & 23 & $p=.01$ \\
AR-Based Indoor & Had Difficulty & 33 & 27 & $\mathrm{df}=1$ \\
Navigation Awareness & No Difficulty & 10 & 1 & $\mathrm{x}^{2}=0.09$, \\
& Total & 43 & 28 & $p=.93$ \\
\hline
\end{tabular}

Table 4 reports the number of students having difficulty finding their particular room when they first arrived at the university's residence halls and the need to have extra time when searching. The result shows a significant association between the two variables, $\mathrm{x}^{2}$ $(1)=5.80 ; p<.01$. It indicates that when students are having difficulty searching, they will require additional time. Also in Table 4 reports the number of students having difficulty searching and their awareness of existing AR-based indoor navigation applications. There was no significant association between the number of students who had difficulty searching and their awareness, $\mathrm{x}^{2}(1)=0.09 ; p>.05$. However, Table 4 shows that students who had difficulty searching are primarily aware of AR-based indoor navigation in the 
Table 5

AR usage experience and preferable method when finding room of both genders

\begin{tabular}{lllll}
\hline & Genders & Yes & No & Chi - Square \\
\hline \multirow{2}{*}{$\begin{array}{l}\text { Experience in using existing AR } \\
\text { Indoor Application }\end{array}$} & Male $(\mathrm{n}=36)$ & 3 & 33 & $\mathrm{df}=1$ \\
& Female $(\mathrm{n}=35)$ & 1 & 34 & $\mathrm{x}^{2}=1.00$, \\
& Total & 4 & 67 & $p=.32$ \\
Preferable Method (Conventional & Male $(\mathrm{n}=36)$ & 29 & 7 & $\mathrm{df}=1$ \\
Vs AR) & Female $(\mathrm{n}=35)$ & 27 & 8 & $\mathrm{x}^{2}=0.12$, \\
& Total & 56 & 15 & $p=.72$ \\
\hline
\end{tabular}

market. Therefore, it could be a good reason for fostering the Student Residence AR indoor navigation.

Table 5 reports the students' experience in using any existing AR-based indoor navigation applications. Both male and female students have never used any AR-based indoor navigation applications, and the proportion between both genders shows no difference, $x^{2}(1)=1.00 ; p>.05$. Also, Table 5 reports the preferable practice of searching for a room in the residence halls between conventional or an AR-based indoor navigation application. Again, there is no difference in proportion $\left(\mathrm{x}^{2}(1)=0.12 ; p>.05\right)$ between both genders as to the preferable practice in searching a room. Nevertheless, both genders show interest in using a Student Residence AR indoor navigation application within the campus.

The preliminary study results reported that most of the respondents were aware and interested in having an AR-based indoor navigation application. Although most respondents have not previously experienced or used AR-based indoor navigation applications such as the proposed Student Residence AR indoor navigation application, they are still interested in using it because of its convenience. This preliminary study also identified that the more the students have difficulty searching, the more they require additional time to reach their destination and seek help from others. Only a tiny percentage of students did not ask for assistance when they first arrived at the university's halls of residence.

Furthermore, a small-scale prototype of the Student Residence AR indoor navigation application within a house was developed to test and identify technical requirements for a more significant scale application development. The aim was to minimise the technical errors that could result in a delay or ineffective large-scale application. Figure 5 presents the interfaces and flow of the application.

Figure 4(a) shows the homepage of the Student Residence AR indoor navigation application prototype. Figure 4(b) shows the 'Scan page' of the application where users need to search for the AR marker and scan it via their phone camera. The marker is used to trigger the application. It will then load and direct the user to the 'Selection page', as shown in Figure 4(c). Here, users are required to choose one of the destinations (e.g., Living Room, store and kitchen). Once a preferable destination has been selected, users are directed 
to the 'Path Display pages', as shown in Figures 4(d) and 4(e). These pages show the path with arrows leading to the preferred destination. Users can follow the arrows until they reach the intended destination. Upon arrival at the destination, a message 'You've reached Destination' will appear, as shown in Figure 4(f). Users can then quit the application by going back to the 'Selection Page' and tap on the 'Exit' button, as shown in Figure 4(g).

In this prototype development, the canvas allows users to interact with the AR device via buttons, as presented in Figure 5. Panel 1 and 2 of the canvas layers have different button functions that help direct users to specific destinations.

Also, a floor plane (the 3D flat surface in Unity) is created to allow the application to understand the navigational area, as shown in Figure 6. The blue area of the floor plane represents walkable areas, whereas the pink and grey $3 \mathrm{D}$ objects represent non-walkable areas. A baking process is carried out to allow the application to understand these two distinct areas. In addition, the AR camera object is used as a first-person view of the application and acts as a virtual human on the floor plane. In this situation, the AR camera object will also move when the user moves the application.

Furthermore, to guide the users to go from the current location to the destination location via the indoor application, a navigation controller script was created using the $\mathrm{C \#}$ programming language to display a $3 \mathrm{D}$ path. Nevertheless, in this prototype, the line was replaced with an arrow-pattern-like path to make it more visible and pleasant for the users

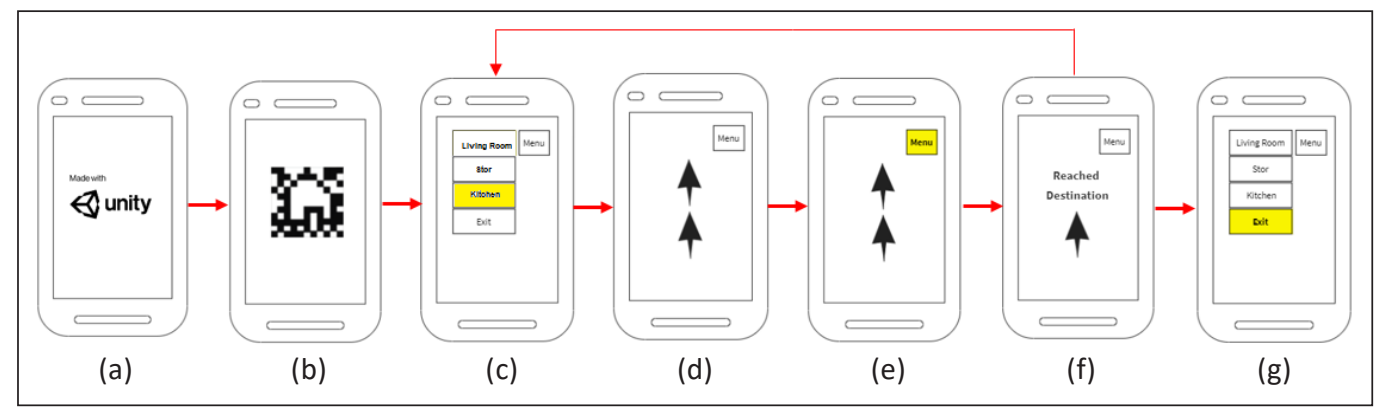

Figure 4. Interface design and the AR Indoor navigation prototype flow

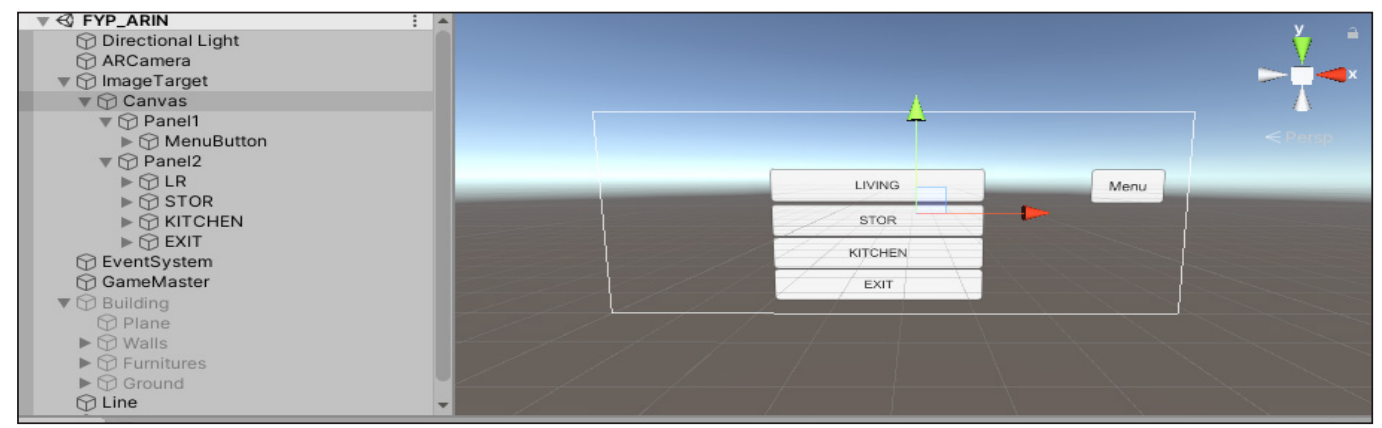

Figure 5. Panel 1 and Panel 2 of the Canvas layers created 


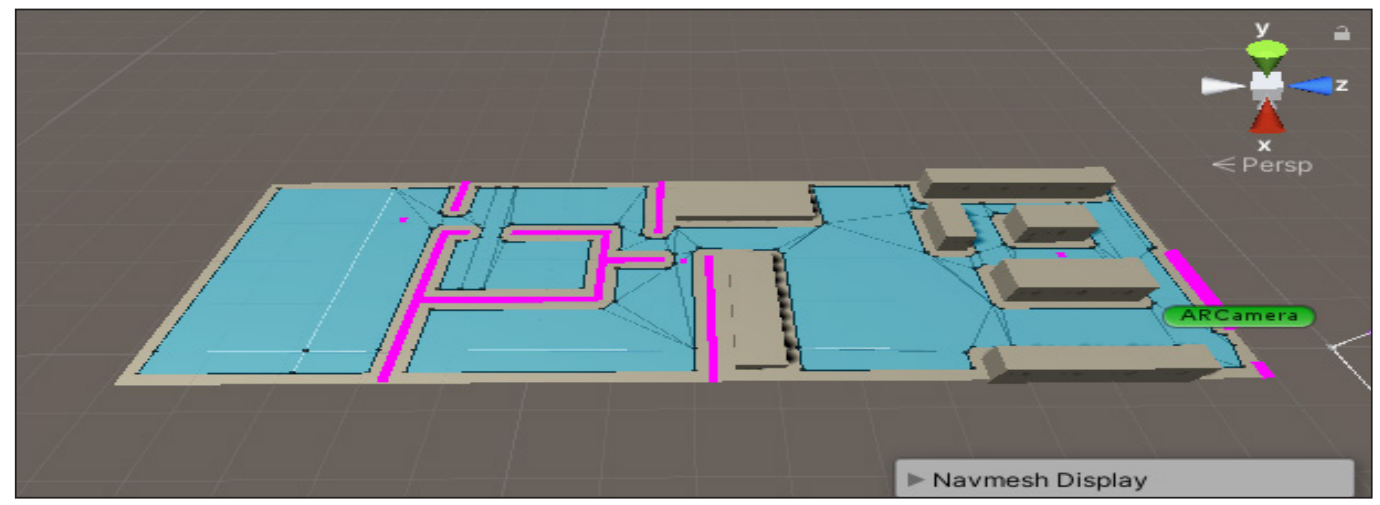

Figure 6. The walkable and non-walkable area of the floor plane

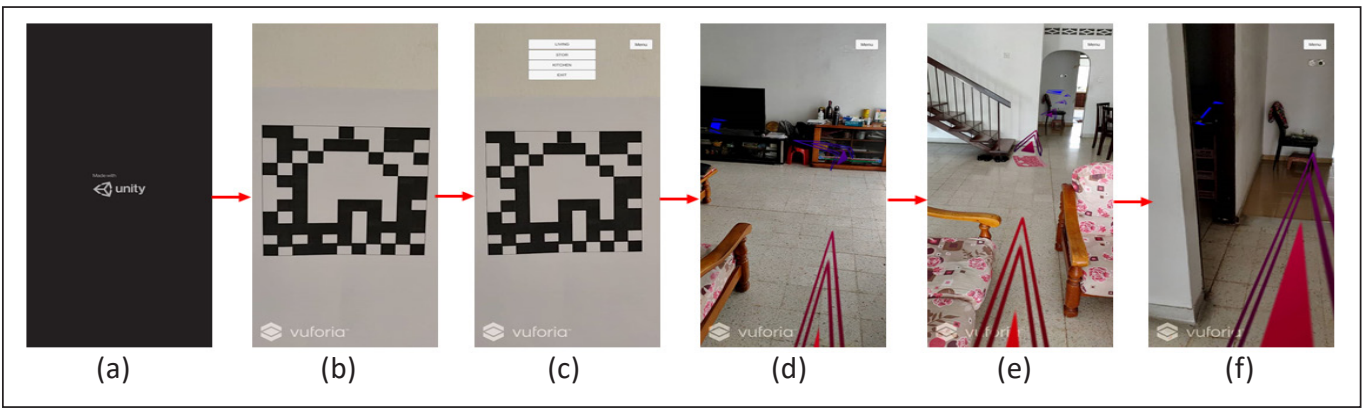

Figure 7. The Student Residence AR indoor navigation application demonstration

[Figures 7(d), 7(e) and 7(f)]. A voice narrative is also integrated along the arrow-patternlike path to assist navigation. Demonstration of the AR-based indoor navigation prototype, which leads to the kitchen of a house (pilot scale), is presented in Figure 7.

Four evaluators were involved in the prototype test. Two of the evaluators had experience with AR development, one had used AR before, and the other had never used any AR application before. In a closed experimental area, the evaluators were given the AR-based indoor navigation application and were informed to use the application to reach a destination. However, the evaluators had no idea how the closed experimental area was set up. Overall, the development of a small-scale prototype resulted in a number of practical technical issues.

\section{Improving Arrow Paths}

Although the arrow path correctly directs users to their destination with the help of the voice narration, the arrow-pattern-like path makes it irritating and confusing for users to follow because the arrow-pattern-like path occasionally appears in mid-air or above eye level when panned around. Since it is critical to avoid potential user confusion when designing a UI navigation app (Huang et al., 2020), the arrow-pattern-like path will be 
improved in the large-scale development phase by including a standard line alongside the arrow-pattern-like path to avoid confusion.

\section{Distance Accuracy}

Two evaluators discovered problems with distance accuracy due to the small number of AR markers used in the navigation and floor plane to reach the destination. Compared to markerless AR navigations that use GPS, this indoor navigation employs AR markers. However, the number of AR markers used will affect the distance accuracy as each AR marker can only cover a small navigation area. According to Rehman \& Cao (2017), a more complex environment and longer route may improve accuracy and performance. Therefore, for large-scale development, more AR markers are needed to reduce distance accuracy errors.

\section{Assistive Guidelines}

The application was confusing in the beginning because the evaluators did not know what to do. This situation made the application challenging to use and non-user-friendly. Therefore, in the large-scale project, it is necessary to add an assistive guideline to provide users with clear step-by-step recommendations when using the application in contrast to Rehman and Cao (2017) suggestion of not to use any assistive guideline to study retention routes in indoor navigations.

\section{Complicated Software Development Kit}

Both AR Core and Vuforia are useful software development kits (SDKs) that enable AR application development. However, the AR navigation in the pilot study is developed using Unity. When using AR Core, all AR components were stored in separate folders causing the developer to unfold each folder, learn one by one, understand and use each component. However, when using Vuforia, the components were nicely arranged on a fixed panel in Unity, ready to be used. This arrangement makes the development process easier and smoother. Furthermore, AR Core dedicates to location-based navigation using SLAM (Simultaneous Localisation and Mapping) algorithms (Morar et al., 2020). In contrast, Vuforia dedicates to marker-based navigations using their plane-find technology, as in Figure 6 (Vuforia Library, 2021). Therefore, Vuforia will be applied in the large-scale development due to the project implementation in an indoor static environment.

The implementation of this small-scale prototype revealed a few other issues that must be addressed before moving forward with the large-scale prototype in the university. Because the student residence halls cover such a large area, multiple routes may arise when using the AR indoor navigation application. As a result, a more complicated rerouting process is required. One solution to this could include a feature in the application that 
allows users to choose a route based on the total time to get to their destination before continuing their journey. Aside from that, the ease of use of the AR indoor navigation application should also be taken into consideration. Allowing the user to interact with the app with ease will increase engagement and encourage long-term usage. Incorporating a mixed reality environment, such as allowing users to interact with the application using gesture recognition or an assistant avatar, could be convenient. However, keeping confusion and burden to a minimum should be regarded.

\section{CONCLUSION}

Searching for a place or room in the student halls of residence for new students is sometimes an unpleasant experience, especially when there is so much luggage to carry during registration. This paper aims to perform a feasibility study of applying a Student Residence AR indoor navigation application and identify technical issues through a small scale prototype development within a small navigational area. The four critical issues discussed include improving arrow paths, distance accuracy, assistive guidelines, and software development kit difficulty.

The next phase of this study is to implement the Student Residence AR indoor navigation application on a larger scale, the university's halls of residence, and to evaluate the application among new students entering the university. In addition, the Covid-19 Pandemic has introduced a new norm for physical distancing in the fight against the outbreak. Therefore, this application may embrace physical distancing during this challenging time, and at the same time, expose the student to a virtual campus environment.

\section{ACKNOWLEDGEMENT}

The authors would like to express their gratitude to Universiti Malaysia Sabah (UMS) for providing the necessary resources for this research. Thank you also to all of the undergraduates who volunteered their time and effort with this study.

\section{REFERENCES}

Arantes, W. V., \& Lamounier Jr, E. A. (2018). A strategy for the use of indoor and outdoor augmented reality location systems applied to smartphones. IEEE Latin America Transactions, 16(5), 1460-1467. https:// doi.org/10.1109/TLA.2018.8408442

Billinghurst, M., Clark, A., \& Lee, G. (2014). A survey of augmented reality. Foundations and Trends in Human-Computer Interaction, 8(2-3), 73-272. https://doi.org/10.1561/1100000049

Bui, D. T., Barnett, T., Hoang, H. T., \& Chinthammit, W. (2021). Tele-mentoring using augmented reality technology in healthcare: A systematic review. Australasian Journal of Educational Technology, 37(4), 81-101. https://doi.org/10.14742/ajet.6243 
Cai, S., Liu, E., Yang, Y., \& Liang, J. C. (2019). Tablet-based AR technology: Impacts on students' conceptions and approaches to learning mathematics according to their self-efficacy. British Journal of Educational Technology, 50(1), 248-263. https://doi.org/10.1111/bjet.12718

Chanphearith, S., \& Santoso, A. J. (2016). Analysis and implementation of location-based augmented reality mobile application for searching tourist attractions and culinary places in Phnom Penh. International Journal of Computer Science Trends and Technology (IJCST), 4(6), 126-136.

Codina, M., Castells-Rufas, D., Carrabina, J., Salmon, I., Ayuso, N., Guerendiain, A., \& Alvarez, G. (2019). Augmented reality for emergency situations in buildings with the support of indoor localization. In Multidisciplinary Digital Publishing Institute Proceedings (Vol. 31, No. 1, p. 76). MDPI Pubishing. https://doi.org/10.3390/proceedings2019031076

de Oliveira, L. C., Andrade, A. O., de Oliveira, E. C., Soares, A. B., Cardoso, A., \& Lamounier Jr, E. A. (2017). Indoor navigation with mobile augmented reality and beacon technology for wheelchair users. In 2017 IEEE EMBS International Conference on Biomedical \& Health Informatics (BHI) (pp. 37-40). IEEE Publishing. https://doi.org/10.1109/BHI.2017.7897199

de Oliveira, L. C. , Soares, A. B., Cardoso, A., de Oliveira Andrade, A., \& Lamounier Jr, E. A. (2016). Mobile augmented reality enhances indoor navigation for wheelchair users. Research on Biomedical Engineering, 32(2), 111-122. https://doi.org/10.1590/2446-4740.01515

Dong, W., Wu, Y., Qin, T., Bian, X., Zhao, Y., He, Y., Xu, Y., \& Yu, C. (2021). What is the difference between augmented reality and 2D navigation electronic maps in pedestrian wayfinding? Cartography and Geographic Information Science, 48(3), 225-240. https://doi.org/10.1080/15230406.2021.1871646

Edwards-Stewart, A., Hoyt, T., \& Reger, G. M. (2016). Classifying different types of augmented reality technology. Annual Review of CyberTherapy and Telemedicine, 14(January), 199-202.

Gerstweiler, G. (2018). Guiding people in complex indoor environments using augmented reality. In 2018 IEEE Conference on Virtual Reality and 3D User Interfaces (VR) (pp. 801-802). IEEE Publishing. https:// doi.org/10.1109/VR.2018.8446138

Gerup, J., Soerensen, C. B., \& Dieckmann, P. (2020). Augmented reality and mixed reality for healthcare education beyond surgery: An integrative review. International Journal of Medical Education, 11, 1-18. https://doi.org/10.5116/ijme.5e01.eb1a

Ghantous, M., Shami, H., \& Taha, R. (2018). Augmented reality indoor navigation based on Wi-Fi trilateration. International Journal of Engineering Research \& Technology (IJERT), 7(07), 396-404.

Huang, B. C., Hsu, J., Chu, E. T. H., \& Wu, H. M. (2020). Arbin: Augmented reality based indoor navigation system. Sensors (Switzerland), 20(20), 1-20. https://doi.org/10.3390/s20205890

Jumarlis, M., \& Mirfan, M. (2018). Implementation of markerless augmented reality technology based on android to introduction lontara in marine society. In IOP Conference Series: Earth and Environmental Science (Vol. 156, No. 1, p. 012017). IOP Publishing. https://doi.org/10.1088/1755-1315/156/1/012017

Kato, Y., \& Yamamoto, K. (2020). A sightseeing spot recommendation system that takes into account the visiting frequency of users. ISPRS International Journal of Geo-Information, 9(7), Article 411. https:// doi.org/10.3390/ijgi9070411 
Khan, D., Ullah, S., \& Nabi, S. (2019). A generic approach toward indoor navigation and pathfinding with robust marker tracking. Remote Sensing, 11(24), 1-21. https://doi.org/10.3390/rs11243052

Khan, R. U., Oon, Y. B., Madihie, A., \& En, C. S. (2019). Indoor navigation systems using annotated maps in mobile augmented reality. International Journal of Innovation, Creativity and Change, 8(2), 1-14.

Morar, A., Balutoiu, M. A., Moldoveanu, A., Moldoveanu, F., Butean, A., \& Asavei, V. (2020). Evaluation of the ARCore indoor localization technology. In 2020 19th RoEduNet Conference: Networking in Education and Research (RoEduNet) (pp. 1-5). IEEE Publishing. https://doi.org/10.1109/RoEduNet51892.2020.9324849

Rehman, U., \& Cao, S. (2017). Augmented-reality-based indoor navigation: A comparative analysis of handheld devices versus google glass. IEEE Transactions on Human-Machine Systems, 47(1), 140-151. https:// doi.org/10.1109/THMS.2016.2620106

Sani, Z. H. A., Huiyi, A. S., Hong, T. S., Nizam, D. N. M., \& Baharum, A. (2020). Design and development of an augmented reality application to learn Mandarin. European Journal of Molecular \&amp; Clinical Medicine, 7(8), 3814-3826.

Sasaki, R., \& Yamamoto, K. (2021). Sightseeing navigation system from normal times to disaster outbreak times within urban tourist areas in Japan. Applied Sciences, 11(10), Article 4609. https://doi.org/10.3390/ app11104609

Satriadi, K. A., Ens, B., Cordeil, M., Jenny, B., Czauderna, T., \& Willett, W. (2019). Augmented reality map navigation with freehand gestures. In 2019 IEEE Conference on Virtual Reality and $3 D$ User Interfaces (VR) (pp. 593-603). IEEE Publishing. https://doi.org/10.1109/VR.2019.8798340

Siltanen, S. (2012). Theory and applications of marker-based augmented reality: Licentiate thesis (Issue 3). VTT Technical Research Centre of Finland.

Tran, T. T. M., \& Parker, C. (2020). Designing exocentric pedestrian navigation for AR head mounted displays. In Extended Abstracts of the 2020 CHI Conference on Human Factors in Computing Systems (pp. 1-8). ACM Publishing. https://doi.org/10.1145/3334480.3382868

Uchida, N., Tagawa, T., \& Sato, K. (2017). Development of an augmented reality vehicle for driver performance evaluation. IEEE Intelligent Transportation Systems Magazine, 9(1), 35-41. https://doi.org/10.1109/ MITS.2016.2601943

Vargas, J. C. G., Fabregat, R., Carrillo-Ramos, A., \& Jové, T. (2020). Survey: Using augmented reality to improve learning motivation in cultural heritage studies. Applied Sciences, 10(3), Article 897. https:// doi.org/10.3390/app10030897

Verma, P., Agrawal, K., \& Sarasvathi, V. (2020). Indoor Navigation using augmented reality. In Proceedings of the 2020 4th International Conference on Virtual and Augmented Reality Simulations (pp. 58-63). ACM Publishing. https://doi.org/10.1145/3385378.3385387

Vidhyavani, A., Stanly, S., Pandey, A. K., \& Choudhury, S. (2019). Combination of real and virtual world for indoor navigation using mobile application. International Journal of Engineering and Advanced Technology, 8(4), 307-310.

Vuforia Library. (2021). Using ARCore with Vuforia engine. Retrieved May 20, 2021, from https:/library. vuforia.com/articles/Solution/arcore-with-vuforia.html 
Williams, M., Yao, K. K. K., \& Nurse, J. R. C. (2020). Developing an Augmented reality tourism app through user-centred design (extended version). ArXiv Publishing.

Yang, G., \& Saniie, J. (2017). Indoor navigation for visually impaired using AR markers. In 2017 IEEE International Conference on Electro Information Technology (EIT) (pp. 1-5). IEEE Publishing. https:// doi.org/10.1109/EIT.2017.8053383

Yoon, C., Louie, R., Ryan, J., Vu, M. K., Bang, H., Derksen, W., \& Ruvolo, P. (2019). Leveraging augmented reality to create apps for people with visual disabilities: A case study in indoor navigation. In The 21st International ACM SIGACCESS Conference on Computers and Accessibility (pp. 210-221). ACM Publishing. https://doi.org/10.1145/3308561.3353788

Yung, R., \& Khoo-Lattimore, C. (2019). New realities: A systematic literature review on virtual reality and augmented reality in tourism research. Current Issues in Tourism, 22(17), 2056-2081. https://doi.org/10 $.1080 / 13683500.2017 .1417359$ 
